\title{
Más allá del Duero: La Guerra de Sucesión en EXTREMADURA (1475-1477)
}

\author{
Carlos J. Rodríguez Casillas ${ }^{1}$ \\ Universidad de Extremadura
}

\begin{abstract}
Resumen
El estudio de las campañas militares que acontecieron en el marco de los primeros años de la Guerra de Sucesión castellana de 1475 se ha realizado, de forma tradicional, en base a la actividad bélica que los protagonistas de este conflicto desplegaron en el valle del Duero. Es por ello que, mediante este estudio, trataremos de poner de relieve la importancia que tuvieron los territorios de la periferia de Castilla en esta primera fase del conflicto. Para ello, vamos a tomar como referente lo ocurrido entre los años de 1475 y 1477 en uno de los frentes más violentos de este enfrentamiento, como fue el caso de la frontera luso-extremeña.
\end{abstract}

\section{Palabras clave}

Guerra medieval; Guerra de Sucesión Castellana; Reyes Católicos; frontera.

\begin{abstract}
This paper analyses the first military campaigns of the War of Castilian Succession, contested from 1475 to 1479 . From a traditional perspective, investigation had focused on the conflicts around the Douro, although in this work we aim to highlight the importance of Castilian peripheral territories during the first stages of the war, especially in the border between Portugal and Extremadura, one of the most violent fronts between 1475 and 1477.
\end{abstract}

Key words

Medieval warfare; War of Castilian Succession; Catholic Kings; border.

\section{Resumo}

O estudo das campanhas militares, que tiveram lugar no contexto dos primeiros anos da Guerra de Sucessão de Castela de 1475 tem sido feito, tradicionalmente, com base na atividade militar dos protagonistas deste conflito no Vale do Douro. É por isso que, através deste estudo, tentamos destacar a importância que os territórios da periferia de Castela tiveram nesta primeira fase do conflito. Para este fim, tomaremos como referência o que aconteceu entre os anos de 1475 e 1477 numa das áreas mais violentas deste confronto militar, como foi o caso da fronteira luso-extremenha.

\section{Palavras-chave}

Guerra Medieval; Guerra de Sucessão de Castela; Reis Católicos; fronteira.

\footnotetext{
Universidad de Extremadura. Correo electrónico: crguezcasillas@gmail.com.
} 


\section{Introducción}

Tradicionalmente el estudio de la Guerra de Sucesión castellana de 1475 se ha articulado en torno a dos periodos. El primero de ellos, que suele identificarse con la verdadera lucha por el trono de Castilla, se inicia con la invasión de Alfonso V de Portugal en 1475 y culminaría con los hechos de armas ocurridos tras la batalla de Toro y el repliegue de los portugueses a su reino a finales de 1476. Por el contrario, el segundo (que transcurre entre 1478 y 1479), más que una continuación de la lucha por la legitimidad de la Corona castellana, se va a caracterizar por ser una guerra de carácter internacional entre Castilla y Portugal, donde ambas potencias dirimirían antiguas rivalidades de índole comercial y territorial ${ }^{2}$.

Normalmente, la primera fase de la contienda ha sido estudiada en base a la actividad militar que Alfonso V y Fernando el Católico desplegaron en el valle del Duero. Lógicamente, ello ha permitido tener un conocimiento detallado del desarrollo de la guerra en este ámbito geográfico, pero en contrapartida ha relegado a un segundo plano lo sucedido en otros territorios, como los de frontera ${ }^{3}$.

Ahora bien, si analizamos en su conjunto las campañas militares que tuvieron lugar durante el comienzo de la Guerra de Sucesión, en vez de centrar el foco de atención en la actividad militar de los protagonistas del conflicto, el contexto bélico que se nos presenta es totalmente diferente, pudiendo apreciarse la existencia de dos espacios de actuación bastante definidos (Meseta/frontera) que tuvieron una gran actividad militar, y que se encontraban mucho más vinculados de lo que en principio pudiera imaginarse.

Es por todo este conjunto de razones por las que consideramos que el tratamiento que se le ha venido dando a la participación de los territorios de frontera durante este primer

2 Luis SuÁrez Fernández, Los Reyes Católicos. La conquista del trono, Rialp Ediciones, Madrid, 1989, p. 157.

3 En este sentido, una gran parte de las obras que abordan el reinado de los Reyes Católicos, suelen analizar el conflicto sucesorio en base a la actividad militar llevada a cabo por Alfonso V y Fernando el Católico, dedicando solamente unas breves líneas a los hechos de armas ocurridos en la citada frontera, entre 1475-76. Como puede apreciarse en: W. Prescott Historia del reinado de los Reyes Católicos, D. Fernando y Dña. Isabel, Gaspar Roig Ed., Madrid, 1855; M. Á. Ladero Quesada, Los Reyes Católicos: La Corona y la unidad de España, Ed. Asociación López de Gomara, Valencia, 1989; Luis SuÁrez Fernández y Juan de Mata Carriazo, "La España de los Reyes Católicos (1474-1516)", Historia de España, (dir.) J. M. Jover Zamora, Espasa-Calpe, Madrid, 1995; Joseph Pérez, Isabel y Fernando. Los Reyes Católicos, Ed. Nerea, Madrid, 1988; o John Edwards, La España de los Reyes Católicos: 1474-1520, Crítica, Barcelona, 2001. Situación que se repite, incluso, en obras especializadas o que abordan diversos aspectos militares ocurridos durante el reinado de Isabel y Fernando, como son los casos de: Jorge VIGÓN, El ejército de los Reyes Católicos, Editora Nacional, Madrid, 1968; F. CASTILlo, "Guerra, ejército y sociedad en el reinado de Isabel la Católica", Artillería y fortificaciones en la Corona de Castilla durante el reinado de Isabel la Católica. 1474-1504, Aurelio Valdés (coord.), Ministerio de Defensa y Ediciones del Umbral, Madrid, 2004. pp. 56-57. Vicente Á. Álvarez Palenzuela, La guerra civil castellana y el enfrentamiento con Portugal, Biblioteca virtual cervantes, Alicante, 2006. Dirección web de la obra: http://www.cervantesvirtual.com/ obra-visor/la-guerra-civil-castellana-y-el-enfrentamiento-con-portugal-14751479-0/html/00de62f8-82b211df-acc7-002185ce6064.html; o L. Martínez Peña y M. Fernández Rodríguez, La guerra y el nacimiento del Estado Moderno, Véritas, Valladolid, 2014. 
periodo de la Guerra de Sucesión debe corregirse, puesto que algunos frentes fronterizos, como fue el caso del extremeño o el andaluz, cobraron un significativo valor estratégico, precisamente, por su carácter limítrofe con el enemigo portugués.

\section{La importancia de los territorios de frontera en el contexto de la Guerra de Sucesión}

Desde la segunda mitad del siglo XIV, los desequilibrios políticos que tuvieron Castilla y Portugal conllevaron una exacerbada actividad militar que se proyectó en la frontera ${ }^{4}$. La Guerra de Sucesión de 1475 no fue una excepción. Bien es verdad que, a primera vista, la periferia castellana no parece que tuviera una significativa relevancia en el desarrollo de los acontecimientos, al menos en lo que respecta con la guerra que se estaba librando en la Meseta. No obstante, tanto para Castilla como para Portugal, estos territorios cobraron un gran significado geo-estratégico, por lo que debían ser protegidos a toda costa.

Para los Reyes Católicos la frontera representó un espacio que había que dominar en todo momento. Así lo dejaron entrever los jóvenes monarcas en 1476, cuando argumentaron que sus intereses en esta guerra podían verse muy perjudicados si una parte de las plazas fronterizas que jalonaban y defendían dicho espacio llegaban a caer en manos de sus adversarios ${ }^{5}$. $\mathrm{Y}$ es que si los Reyes Católicos pretendían concentrar sus esfuerzos contra Alfonso V en el corazón de Castilla, debían disponer de unas fronteras seguras y bien defendidas. Como advirtieron los propios contemporáneos:

"con las espaldas que tenían seguras por los otros cavalleros e gentes que asy mesmo facían la guerra por las otras partes de la dicha frontera, sus Reales Señorías estaban descargadas de todo lo de estas partes de la dicha Extremadura, $i$ habian buen lugar de proveer $i$ dar remedio en las cosas que tenian entre manos en aquellas partes de Toro i Çamora, donde estaba el dicho adversario".

\footnotetext{
4 Juan L. De La Montaña Conchiña, "Guerra y sociedad en la frontera castellano-portuguesa durante el siglo XIV. El ámbito extremeño-alentejano”, VI Jornadas Luso-Espanholas de Estudos Medievais. A guerra e a sociedade na Idade Média, Ed. Sociedade Portugesa de Estudos Medievais, 2009, p. 502. En verdad, el estado de militarización que sufrió la frontera durante la Baja Edad Media fue una realidad latente. Un claro ejemplo fue que la monarquía castellana solía mantener 100 hombres de caballo en la ciudad de Badajoz (una de las plazas fronterizas más expuestas a los ataques portugueses) para que estuviesen prestos a la hora de hacer la guerra en el interior de Portugal, cuando fuese necesario. João Gouveia Monteiro y Miguel Gómes Martins, As cicatrizes da guerra no espaço froteiriço portugués (1250-1450), Ed. Palimage, Coimbra, 2010, p. 19.

5 Bonifacio Palacios Martín (dir.), Colección diplomática medieval de la Orden de Alcántara. Volumen II, Editorial Complutense, Madrid, 2003, doc. 1.212.

6 Pedro de Orozco y Juan de la Parra, Primera historia de la Orden de Santiago, Transcripción del Marqués de Siete Iglesias, Dip. Provincial, Badajoz, 1978, p. 400.
} 
Por su parte, Alfonso V de Portugal también trató de dominar dicho espacio geográfico, puesto que, si quería actuar con plena libertad en el interior de Castilla, debía de evitar que las acciones militares se trasladasen al interior de Portugal. Para ello delegó en su hijo la defensa del reino ${ }^{7}$ y estableció un buen número de destacamentos a lo largo de todo el perímetro fronterizo ${ }^{8}$. Aunque, como destaca Oliveira Marques, la mayor preocupación de los portugueses fue la protección y reparación de sus plazas fronterizas 9 .

\section{El frente extremeño entre 1475 y 1476: articulación militar y actividad bélica}

Cuando en mayo de 1475 Alfonso V de Portugal invadió Castilla por la zona de Arronches $^{10}$, los Reyes Católicos actuaron con contundencia ante la llegada de tales noticias, declarando la guerra tanto al vecino reino portugués como al resto de la nobleza rebelde que apoyaba su causa ${ }^{11}$.

En principio, mientras el grueso del ejército invasor se encontró en Extremadura, la actividad militar del bando isabelino se centró en intentar resistir la entrada ${ }^{12}$, hostigando a las huestes lusas. Como puede comprobarse a través de la correspondencia personal de Fernando el Católico:

"por Don Francisco de Solís, electo de Alcantara, por Diego de Cáceres, criado de Vuestra Alteza, por Alonso Puertocarrero, por Ciudat Rodrígo, Caceres y Badajoz, que son por todos más de mil de cauallo, se le ha fecho tal recibimiento en su entrada, que le han destrozado mas de doçientos de cauallo"13.

No obstante, una vez que el ejército portugués abandonó la región extremeña y se encaminó hacia los territorios de la Meseta, consolidando su poder territorial en el área del Duero, la actuación bélica de los Reyes Católicos se organizó en torno a dos frentes: uno en el corazón de Castilla (donde se encontraba Alfonso V), y otro situado en la

\footnotetext{
García de Resende, Vida e feitos D’El Rey Dom João II, Edición crítica de Evelina Verdelho, CELGA, Coimbra, 2007, cap. IX.

8 Alonso de Maldonado, Vida e historia del Maestre de Alcántara don Alonso de Monroy, edición de Leonardo Romero, Ediciones Tárraco, Tarragona, 1978, p. 126.

9 Antonio H. de Oliveira Marques, Portugal na Crise dos Séculos XIV e XV, Ed. Presença, Lisboa, 1987, p. 346. Ver también: Alonso de Palencia, Crónica de Enrique IV. Introducción de Paz y Meliá, volumen II, Atlas, Madrid, 1975, p. 184.

10 Luis SuÁrez Fernández, La conquista del trono..., pp. 116-120.

11 Antonio de la Torre y Luis SuÁrez Fernández (eds.), Documentos referentes a las relaciones con Portugal durante el reinado de los Reyes Católicos, volumen I, CSIC, Valladolid, 1958, doc. 20.

12 Ibidem.

13 Antonio Paz y Melía, El cronista Alonso de Palencia, Madrid, 1914, doc. 83.
} 
frontera con Portugal. Las propias instrucciones dadas por Isabel la Católica a algunos de sus capitanes del frente extremeño parecen corroborar lo indicado:

"Al qual dicho rey de Portogal, con ayuda de Nuestro Señor, el dicho rey, mi señor, entiende muy presto yr a buscar, donde quier que estoviere, e darle batalla campal. Y entre tanto es mi merçed e voluntad de mandar faser la guerra, a fuego e a sangre, al dicho rey de Portogal. E para la faser he dado cargo al honrado maestre don Alfonso de Cárdenas, e le enviado a mandar que faga la dicha guerra al dicho reyno de Portogal, a fuego e a sangre, entrando en el dicho reyno de Portogal e tomando e devastando e destruyendo qualesquier villas e logares" 14.

En este sentido, el hecho de que Fernando el Católico asumiera las riendas de los ejércitos castellanos en el valle del Duero obligaba a los monarcas a dotar de una estructura militar jerarquizada los territorios de frontera. Así, tomando como referente el caso de Andalucía, Isabel y Fernando concedieron un enorme poder de actuación al duque de Medina Sidonia, como capitán general de toda la frontera andaluza ${ }^{15}$. En el caso concreto del frente extremeño, el mando militar de esta provincia recayó en Gómez Suárez de Figueroa, II conde de Feria ${ }^{16}$. En verdad, Suárez de Figueroa tenía una dilatada experiencia al frente de la defensa de este territorio. No en vano, Enrique IV ya le había conferido la defensa de todo este distrito en dos ocasiones: en $1464^{17} \mathrm{y}$ en $1474^{18}$. Alonso de Palencia llegó incluso a decir de él que, por aquellos entonces, Figueroa era el "Señor de los pueblos indefensos de aquella frontera"19. En definitiva, eran sobradas las razones por las cuales Isabel vio en el conde de Feria a uno de los pocos hombres capaces de defender sus derechos en una región donde sus intereses podían verse seriamente afectados por las acometidas de los portugueses ${ }^{20}$.

Pero además de Figueroa, los Reyes Católicos fueron capaces de rodearse de importantes apoyos en esta área geográfica, como fueron los casos de Alonso de Cárdenas (comendador mayor de la Orden de Santiago), Francisco Solís (autoproclamado maestre de la Orden de Alcántara), Diego de Ovando (criado de Juan II de Aragón) o Alonso

\footnotetext{
14 Antonio de la Torre y Luis SuÁrez Fernández (eds.), Documentos referentes a ..., volumen I, doc. 23.

15 Paulina Rufo YSERn, "Sevilla, Écija y Carmona en el conflicto castellano-portugués (1475-1479)", Revista da Facultade de Letras, 15-1 (1998), p. 499.

16 José Luis del Pino García, Extremadura en las luchas políticas del siglo XV, Diputación Provincial, Badajoz, 1991, p. 280.

17 Miguel Ángel Ladero Quesada y César Olivera Serrano (dirs.), Documentos sobre Enrique IV de Castilla y su tiempo, volumen I, Universidad Carlos III, Madrid, 2016, doc. 1.888.

18 Miguel Ángel Ladero Quesada y César Olivera Serrano (dirs.), Documentos sobre Enrique IV ..., doc. 3.408.

19 Alonso de Palencia, Crónica de Enrique IV..., volumen II, p. 169.

20 Fernando Mazo Romero, El Condado de Feria, Institución Cultural Pedro de Valencia, Badajoz, 1980, p. 226 .
} 
de Monroy (maestre que fue de la Orden de Alcántara) ${ }^{21}$. A todos estos comandantes se les dotó de un gran poder de actuación ${ }^{22}$. Así, además de situárseles al frente de los recursos y de las tropas de Santiago y Alcántara ${ }^{23}$, los monarcas les otorgaron la potestad militar sobre algunas de las más importantes villas y ciudades de extremeñas.

En conclusión, a pesar de que Alfonso V contaba en Extremadura con significativos apoyos (como era el caso de los Stúñiga en Plasencia, de Beatriz Pacheco en Medellín o de la ciudad de Trujillo, en poder de Diego Pacheco), los Reyes Católicos lograron organizar militarmente con cierto éxito este sector fronterizo, como se expondrá a continuación.

\section{La actividad militar del frente extremeño entre 1475 y 1476}

La actividad militar de este frente se centró en el cumplimiento de dos objetivos: proteger la frontera de las acciones militares de los portugueses y trasladar la guerra al interior de Portugal.

\subsection{Actividad defensiva}

La defensa de este sector fronterizo fue una misión harto complicada. Paradójicamente, no fueron las acometidas de los portugueses las que ocasionaron la desestabilización de este frente, sino las rivalidades que existían entre los propios isabelinos. Y es que, a pesar de militar en el mismo bando, algunos caudillos extremeños se encontraban fuertemente enfrentados entre sí.

Uno de estos casos fue la rivalidad que existía por aquellos entonces entre Alonso de Cárdenas y Suárez de Figueroa ${ }^{24}$, que eran precisamente dos de los principales responsables de velar por la defensa de este frente. Conviene recordar a este respecto que en

21 Para entender mejor las motivaciones que llevaron a estos nobles a unirse a la filas del bando isabelino, ver: Gloria LoRA SERRAno, "Señoríos y frontera: la nobleza extremeña ante la guerra luso-castellana de sucesión”, Revista da Facultade de Letras, Historia, 15-1 (1998), p. 392.

22 En mi opinión, a pesar de las retribuciones que les llegaron a conceder los monarcas a estos capitanes de frontera, creo que ninguno de ellos alcanzó el rango de capitán general, como alguna vez se ha afirmado. Sólo más adelante, a mi juicio desde 1477, parece advertirse una cierta cotitularidad de la defensa militar de esta provincia entre Cárdenas y Figueroa. Una tesis que también es compartida por Fernando MAZO ROMERO en su artículo, "La intervención del II Conde de Feria en la guerra de Sucesión Castellano-Portuguesa", Revista de Estudios Extremeños, 37-2 (1981), p. 429.

23 En el caso concreto de Diego de Ovando, los monarcas le otorgaron la administración de la Orden de Alcántara durante los primeros compases de la guerra, debido a la ingobernabilidad que padecía esta institución por tener tres aspirantes al cargo de maestre enfrentados entre sí (Alonso de Monroy — que se encontraba preso - , el autoproclamado Francisco de Solís y el joven Juan de Stúñiga — cuyo linaje se encontraba enfrentado a Isabel y Fernando-). Posteriormente, dicho capitán marcharía junto al rey Fernando al Duero, estando presente en la batalla de Toro. Para conocer más de este personaje, ver: Miguel MuÑoz DE SAn Pedro, "El capitán Diego de Cáceres Ovando, paladín extremeño de los Reyes Católicos", Revista de Estudios Extremeños, 7-3 (1951), pp. 555-568.

24 Luis SuÁrez Fernández, Los Reyes Católicos..., pp. 114-115. 
el momento de la muerte de Juan Pacheco, Suárez de Figueroa (que había sido designado gobernador de la orden santiaguista ${ }^{25}$ ) trató de impedir que Cárdenas (a la postre comendador mayor de esta institución) tomara posesión de ciertas encomiendas de la orden. Además, Figueroa se posicionó en contra de Cárdenas, al apoyar las aspiraciones de Medina Sidonia al maestrazgo de Santiago ${ }^{26}$. Todo lo cual derivó en una terrible guerra privada entre ambos nobles en los albores de la invasión portuguesa que terminó proyectándose durante el inicio de las hostilidades luso-castellanas ${ }^{27}$.

Lógicamente, una situación como esta resultaba nefasta para los intereses de los monarcas castellanos ${ }^{28}$. Y es que, aunque Suárez de Figueroa pareció desempeñar un destacado papel en la defensa de la ciudad de Badajoz y su tierra ${ }^{29}$ (donde según Rui de Pina se concentraban la mayoría de los ataques portugués $)^{30}$, la seguridad de la frontera, en su conjunto, estuvo en serio peligro. Algunos autores han llegado a afirmar que esta rivalidad interna estuvo a punto de ocasionar la caída de este frente ${ }^{31}$. Hasta tal punto este hecho fue una realidad, que el temor a que se propagara esta confrontación hasta Andalucía, hizo que el duque de Medina Sidonia enviara a Badajoz una embajada compuesta por dos miembros de la Corte (Antonio Rodríguez de Lillo y el cronista Alonso de Palencia), con el objetivo de que ambos pudieran asentar una tregua que estabilizara el frente ${ }^{32}$.

No obstante, habría que esperar a finales de septiembre de 1475 para que, a instancia de sus altezas, ambos capitanes firmaran un compromiso de no agresión ${ }^{33}$. Desde entonces, a raíz de este pacto, la frontera sur extremeña ofrecería una extraordinaria cohesión. No en vano, poco tiempo después de la firma de este tratado de no agresión, Cárdenas y Figueroa actuaron conjuntamente neutralizando las intenciones del príncipe Juan de Portugal de devastar el sur de Extremadura y hacerse con una plaza fuerte ${ }^{34}$. En consecuencia, las fuerzas portuguesas, conscientes desde ese momento de la superioridad militar de los castellanos en este área fronteriza, comenzaron a desplazar sus ataques hacia el sur, más concretamente sobre Encinasola y Cumbres de Bartolomé, ya en Andalucía ${ }^{35}$.

\footnotetext{
25 Miguel Ángel Ladero Quesada y César Olivera Serrano (dirs.), Documentos sobre Enrique IV..., Volumen I, doc. 3.812 .

26 Daniel Rodríguez Blanco, La Orden de Santiago en Extremadura en la Baja Edad Media, Diputación de Badajoz, Badajoz, 1985, p. 51.

27 Andrés Bernáldez, Memorias del reinado de los Reyes Católicos, ed. Manuel de M. Moreno y Juan de Mata Carriazo, Real Academia de la Historia, Madrid, 1962, pp. 87-88.

28 Fernando Mazo Romero en su artículo, "La intervención del II Conde de Feria..., p. 440.

29 Alonso de Palencia, Crónica de Enrique IV..., volumen II, pp. 225-230

30 Rui de Pina, Chrónica D'El-Rei D. Affonso V, Lisboa, 1901, p. 119.

31 Fernando Mazo Romero, El Condado de Feria..., p. 228.

32 Alonso de Palencia, Crónica de Enrique IV ..., volumen II, pp. 224-225.

33 José Luis del Pino García, Extremadura en las..., p. 283.

34 Luis SuÁrez Fernández, La conquista del trono..., p. 148.

35 José Luis del Pino García, Extremadura en las..., p. 283.
} 


\subsection{La actividad ofensiva}

Ante la aparente indefensión del espacio fronterizo portugués, tras la marcha de gran parte de sus ejércitos hacia el interior de Castilla, los territorios de frontera se convirtieron en privilegiadas plataformas desde donde proyectar la guerra contra el interior de Portugal ${ }^{36}$.

En lo que respecta al caso concreto de Extremadura, una de las primeras campañas que se llevó a cabo desde este frente fronterizo fue la protagonizada por Francisco Solís, el "Electo" de la Orden de Alcántara. La acción se produjo durante el verano de 1475, culminando con la toma de la plaza fuerte de Ugüela ${ }^{37}$. Tras esta conquista, los monarcas ratificaron a Solís como titular de esta posición, y pocos días después, le facultaron con el mando militar de Coria, Badajoz, Cáceres y Alburquerque ${ }^{38}$. Pero la esquiva fortuna pronto le retiró su gracia a este capitán: los portugueses cercaron Ugüela ${ }^{39}$ y cuando Solís acudió en socorro de los suyos murió de una lanzada en la ingle ${ }^{40}$.

Una muerte que coincidía en el tiempo con el enfrentamiento privado que mantenían entre sí Cárdenas y Suárez de Figueroa, por lo que bien podemos decir que los intereses de los monarcas en este área geográfica estuvieron en serio peligro. Sin embargo, esta delicada situación cambiaría por completo durante la segunda mitad de 1475. Dos fueron los acontecimientos que propiciaron este hecho: la paz alcanzada entre Cárdenas y Suárez de Figueroa (de la que ya hemos hablado) y la liberación de Alonso de Monroy (uno de los hombres llamados a ser clave en el desarrollo de esta confrontación). Alonso de Palencia llegó incluso afirmar por aquellos entonces que "toda la seguridad de Extremadura parecía depender de la libertad de un solo hombre, del buen clavero de Alcántara, D. Alfonso de Monroy, largo tiempo encerrado en un calabozo"41.

En verdad, la liberación de Monroy fue todo un golpe de efecto en favor de la causa isabelina. Prueba de ello es que este capitán, en tan sólo tres meses, saqueó el señorío placentino de los Stúñiga en varias ocasiones y ganó para los Reyes Católicos la ciudad de Trujillo (hasta entonces en poder de los partidarios del bando juanista) ${ }^{42}$.

\footnotetext{
36 Carlos J. Rodríguez Casillas, A fuego e sangre. La guerra entre Isabel la Católica y Dña. Juana en Extremadura, Editora Regional de Extremadura, Mérida, 2013, p. 37. Ver también: Humbeto Baquero Moreno, "A contenda entre D. Afonso V e os Reis Católicos: incursoes castelhanas no solo portugues de 1475 a 1478", Anais da Academia Portuguesa da Historia, II serie, 25 (1979), pp. 295-324.

37 Alonso de Maldonado, Vida e historia ..., p. 119.

38 Antonio de la Torre y Luis SuÁrez Fernández (eds.), Documentos referentes a ..., volumen I, docs. 28 y 29 .

39 Crónica incompleta de los Reyes Católicos (1469-1476), ed. Julio Puyol, Tipografía de Archivos, Madrid, 1934, p. 253.

40 Esta acción militar fue muy celebrada, perdurando en la memoria colectiva del pueblo portugués. Así, uno de los hijos del capitán luso que dio muerte a Solís, levantó un imponente túmulo en honor a su padre en el Monasterio de San Marcos, a modo de "héroe nacional" que dio su vida en defensa del reino de Portugal. Saul António Gómes, D. Afonso V, Ed. Temas e Debates, Lisboa, 2009, pp. 268-269.

41 Alonso de Palencia, Crónica de Enrique IV ..., volumen II, p. 238.

42 José Luis del Pino García, Extremadura en las..., p. 289.
} 
Además, una vez finalizadas estas campañas por el interior de la geografía extremeña, y antes de que regresara a sus posesiones para pasar el invierno, Monroy se desplazó con sus hombres a la frontera, donde derrotó a los distintos destacamentos portugueses encargados de defender este espacio de las incursiones castellanas. Ya en 1476, en lo que Saul Antonio Gómes alude como una ofensiva castellana en la frontera luso-extremeña ${ }^{43}$, Monroy lideraría una importante campaña militar en el interior de Portugal con la que obtuvo grandes éxitos. Conquistó la fortaleza de Alegrete, derrotó a una avanzadilla portuguesa en la batalla de Guadapero y, junto a Suárez de Figueroa y tropas enviadas por Alonso de Cárdenas, llevó a cabo una intensa labor de devastación del territorio alentejano ${ }^{44}$.

Por último, otro de los capitanes isabelinos que también destacó por sus acometidas en el interior de Portugal fue Alonso de Cárdenas ${ }^{45}$. No sabemos la fecha concreta en la que se llevaron a cabo sus acciones durante esta primera fase del conflicto, aunque todo parece indicar que éstas debieron de ocurrir entre la segunda mitad de 1475 y $1476^{46}$. En cuanto a las campañas que realizó el comendador mayor de León por territorio portugués, convendría destacar las tres grandes incursiones que llevó a cabo sobre el Alentejo (Redondo, Évora y Veiros-Elvas), en las que hurtó una gran cantidad de ganado, además de capturar un significativo número de prisioneros ${ }^{47}$.

\section{Una guerra "a fuego e sangre"}

El conjunto de evidencias anteriormente expuestas, nos sitúa ante una estrategia militar basada en la destrucción del territorio ${ }^{48}$. Lamentablemente, el conocimiento que todavía tenemos sobre las huestes que llevaron a cabo estas acciones, o la propia complejidad y dimensión de este tipo de campañas, resulta todavía muy limitado en comparación con otros hechos de armas contemporáneos, como bien puede ser la batalla de Toro o los asedios de Burgos y Zamora. Un vacío historiográfico que creemos hay que subsanar.

\footnotetext{
43 Saul António Gómes, D. Afonso V..., p. 294.

44 Alonso de Palencia, Crónica de Enrique IV ..., volumen II, p. 282.

45 Andrés Bernáldez, Memorias del reinado..., p. 90.

46 Especialmente porque algunos cronistas suelen relacionar sus campañas con las que estaba desarrollando Monroy por el interior de Portugal en esos momentos. Ver al respecto: Fernando DEL Pulgar, Crónica de los Reyes Católicos, ed. Juan de Mata Carriazo, Espasa Calpe, Madrid, 1943, p. 124.

47 Pedro de Orozco y Juan de La Parra, Primera historia de..., p. 400.

48 Una forma de hacer la guerra que está estrechamente vinculada con la frontera castellano-portuguesa. Así, si tomamos como referente el periodo que va entre 1369 y 1382 (uno de los más conflictivos en este sector fronterizo a raíz de las tensiones políticas que tuvieron Castilla y Portugal desde el ascenso de la dinastía Trastámara y el inicio de las denominadas "guerras fernandinas"), se puede apreciar que la mayoría de las acciones militares no tuvieron su razón de ser en el enfrentamiento en campo abierto. Al contrario, predominaron las pequeñas escaramuzas, los cercos sobre ciudades y, sobre todo, las operaciones militares basadas en la devastación del territorio.
} 


\subsection{Características de las partidas de devastación}

El hecho de que en este sector fronterizo los monarcas delegaran la defensa de sus intereses en la nobleza regional, hace que nos encontremos ante ejércitos privados no muy voluminosos. El potencial militar de los caudillos extremeños así lo demuestra. El jefe militar de esta frontera, Suárez de Figueroa, disponía de una fuerza que llegó a rondar los 300 hombres a caballo y los 3.000 a pie $^{49}$. Cifra que podía verse incrementada si le agregamos el potencial militar de aquellos linajes que se encontraban vinculados al señor de Feria por motivos de dependencia, cercanía o lazos de sangre, como eran los casos de los señores de Alconchel, Villagarcía e Higuera de Vargas ${ }^{50}$. Por su parte, el comendador mayor de Santiago podía llegar a reclutar (entre sus auxiliares y las tropas de guarnición de sus fortalezas) un ejército de 800 lanzas, más un indeterminado número de peones ${ }^{51}$. Posteriormente, ya en 1477, tras hacerse con el maestrazgo, Alonso de Cárdenas pudo mantener de forma constante un ejército de 1.000 lanzas $^{52}$. En el caso de Francisco de Solís, este capitán llegó a reclutar una fuerza compuesta por 200 caballeros y 400 infantes para su campaña contra la posición portuguesa de Ugüela ${ }^{53}$. Y en lo que respecta a Alonso de Monroy, este caudillo solía actuar con una fuerza estable que rondaba los 500 guerreros $^{54}$.

Estos ejércitos fueron comandados por sus propios líderes. No obstante, a pesar de este hecho, muchos de ellos dispusieron de una cadena de mando bastante definida, basada en el sistema de capitanías. Esta realidad se evidencia, especialmente, en el caso concreto de la hueste que Alonso de Monroy utilizó durante sus campañas por el interior de Portugal (gracias, sobre todo, al detallado relato que el cronista Alonso de Maldonado hizo de sus campañas). Así, aunque Monroy actuó como el líder de sus ejércitos, tras él existía toda una serie de oficios intermedios, como era el caso de la figura del capitán. Un cargo que fue desempeñado por aquellos hombres que tenían una dilatada experiencia militar y que, además, disfrutaban de la confianza del propio Monroy.

La adopción de este sistema de capitanías permitía a los caudillos de estas partidas ejecutar los planes de operaciones con una gran eficacia, al poder delegar en estos suboficiales el cumplimiento de objetivos intermedios. Además, estas autoridades militares supervisaban todo el proceso de saqueo del territorio, tratando de evitar que no se produjeran desmanes. Todo lo cual, unido al sentimiento de unidad que les ofrecía su obediencia al líder, hacían de estas partidas, en ocasiones, auténticos destacamentos autónomos ${ }^{55}$, bien cohesionados y disciplinados, logrando un gran nivel de efectividad militar en la guerra ${ }^{56}$.

\footnotetext{
49 Miguel Ángel Ladero Quesada, "La caballería y la población de Extremadura según los alardes de 1502", Norba. Revista de Historia, 17 (2004), p. 167.

50 Gloria Lora SERrano, "Señoríos y frontera..., p. 394.

51 Alonso de Palencia, Crónica de Enrique IV..., volumen II, p. 225.

52 Alonso de Palencia, Crónica de Enrique IV..., volumen II, p. 69.

53 Alonso de Maldonado, Vida e historia..., p. 118.

54 Carlos J. Rodríguez Casillas, D. Alonso de Monroy (s XV), maestre de Alcántara y señor de la guerra, Diputación de Badajoz, Badajoz, 2013, pp. 86-87.

55 La partida de Alonso de Monroy llegó a tener, en este sentido, un gran nivel de autonomía, por cuanto solía salir a pelear con su propio estandarte. Alonso de MALdonAdo, Vida e historia..., p. 123.

56 Carlos J. Rodríguez Casillas, D. Alonso de Monroy..., 105-108.
} 


\subsection{Organización de las incursiones}

Aunque devastar el territorio pueda asemejarse con meros actos anárquicos de destrucción, en verdad esta maniobra necesitaba de una planificación y coordinación previa ${ }^{57}$. En este sentido, más allá de las consabidas levas de hombres, los capitanes debían tener presente ciertas variables.

Una de ellas era fijar la fecha en la que se iba a llevar a cabo la devastación del territorio enemigo. En este sentido, hemos de decir que la época estival constituía el marco perfecto para desplegar este tipo de acciones, por cuanto coincidían en el tiempo con el proceso de recogida de las cosechas, pudiendo ocasionar de esta manera un gran daño sobre la economía del lugar. No en vano, como afirma el profesor García Fitz, las campañas militares solían presentarse como una actividad estacional: se iniciaban en primavera, alcanzaban su punto álgido durante el verano y terminaban con la llegada del invierno ${ }^{58}$. Alonso de Monroy, por ejemplo, tras saquear durante varios meses el espacio fronterizo portugués en 1476, regresó a Castilla para pasar el invierno, puesto que "no había ya qué hacer" en Portugal".

De igual manera, antes de que diera comienzo una determinada campaña, los líderes de estas expediciones debían conocer de antemano la resistencia que podía presentar el territorio que se iba a devastar, con el fin de evitar una posible respuesta armada por parte de los agredidos. Como refleja Alonso de Palencia, con respecto las incursiones que los portugueses llevaban a cabo en el ámbito de la tierra de Badajoz:

"Con tal objeto, los portugueses que habian peleado algunas veces con desgracia contra los vecinos de Badajoz, resolvieron invadir otros lugares, en su entender peor custodiados (...) atacaron Villanueva de Barcarrota, confiados en que, por ser ellos tantos y tan escaso vecindario, les sería fácil" ${ }^{60}$.

Finalmente, había que tener presente ciertos aspectos relacionados con el transcurso de la acción de saqueo. Quizá, uno de los más importantes era establecer cómo debía afrontarse el camino de regreso. Y es que la elección de un mal itinerario o una ralentización del ritmo de marcha a causa del botín acumulado, podía ocasionar que un ejército enemigo diera alcance a la expedición antes de que ésta cruzara de vuelta la frontera. Como podemos apreciar en el caso de la hueste portuguesa que devastó la tierra de Badajoz, durante los primeros compases de la Guerra de Sucesión:

57 Francisco García Fitz, Ejércitos y actividades guerreras en la Edad Media europea, Arco Libros, Madrid, 1998, pp. 28-29.

58 Francisco GArcía Fitz, "El viaje de la guerra", Viajar en la Edad Media, José Ignacio Duarte (coord.), Instituto de Estudios Riojanos, Logroño, 2009, p. 136.

59 Alonso de Maldonado, Vida e historia ..., p. 133.

60 Alonso de Palencia, Crónica de Enrique IV ..., volumen II, p. 225. 
«se apoderaron de cuanto ganado pudieron, y haciendo prisioneros a todos los hombres que encontraron por los campos, regresaron cantando victoria con tan considerable presa. Violo el aguerrido alcaide de Villanueva Fernán Gómez de Solís, y conmovido por los lamentos de la angustiada plebe que quedaba reducida a la miseria, los animó a la persecución del enemigo, a quien lo enorme del botín obligaba a caminar lentamente (...) No se engañó en su cálculo al perseguirlos, y contra la opinión de los que suponían que los portugueses marchaban en completa seguridad, muchos de estos cayeron sin vida a la primera embestida de los castellanos que les fueron a su alcance" 61 .

\subsection{Finalidad estratégica de las incursiones}

Durante muchos años, los estudiosos de la guerra medieval consideraron que este tipo de campañas carecían de objetivo estratégico, por cuanto su fin no era sino el de incendiar y asolar la tierra por el mero disfrute de la violencia ${ }^{62}$. Sin embargo, gracias a la renovación historiográfica que sufrió esta temática a finales del siglo pa$\operatorname{sado}^{63}$, dicha tendencia se vio superada. Así, a través de trabajos como el de García Fitz, hemos podido comprobar que todo este daño que se infligía sobre el territorio no era gratuito, sino que, al contrario, estaba asociado al logro de toda una serie de objetivos estratégicos ${ }^{64}$.

\subsubsection{Desestabilizar a un contrario}

Como afirma Ch. Allmand, los dirigentes militares de la Edad Media fueron plenamente conscientes de los efectos adversos que tenía la destrucción del territorio a la hora de desestabilizar a un enemigo ${ }^{65}$.

En lo que respecta al caso concreto de la confrontación que aquí se está analizando, hemos de decir que las acciones de destrucción del territorio llegaron a tener un gran poder de influencia. Incluso, sobre los ejércitos situados en el valle del Duero. El hecho

\footnotetext{
61 Alonso de Palencia, Crónica de Enrique IV..., volumen II, p. 230.

62 Sean McGlynn, A hierro y fuego. Las atrocidades de la guerra en la Edad Media, Crítica, Barcelona, 2009 , p. 326.

63 Dentro de este proceso de renovación historiográfica quisiera destacar los siguientes trabajos de investigación, David Nicolle Medieval warfare. Source book, Londres, 1996; Michael Prestwich, Armies and Warfare in the Middle Ages: The English Experience, New Haven, 1996; John Gillingham, Richard I, New Haven, 1999; Claude GaIER, Art et organisation militaires dans la Principauté de Liège et dans le comté de Looz au Moyen Age, Bélgica, 1968; Philippe Contamine, La guerra en la Edad Media, Barcelona, 1984; Francisco García Fitz, Castilla León frente al Islam. Estrategias de expansión y tácticas militares, Sevilla, 1998.

${ }^{64}$ Francisco García Fitz, Castilla León frente al Islam... pp. 76-119.

65 Christopher Allmand, "La guerra y los no combatientes en la Edad Media", Historia de la guerra en la Edad Media, (coord.) Maurice Keen, Antonio Machado, Madrid, 2006, p. 336.
} 
de arrasar sistemáticamente el interior de Portugal situaba a Alfonso V ante una terrible disyuntiva: acudir en socorro de su pueblo o seguir con el grueso de su expedición en el Duero. Como recoge al respecto Fernando del Pulgar, el rey de Portugal "quisiera enviar alguna de su gente para resistir aquellos daños que se facían en Portogal; pero reçelaua que por la mengua della reçibiría mayor daño en Castilla, e si no la enviase lo reçibiría en Portogal"

Por su parte, Alonso de Palencia también incide en esta idea, al indicar que:

"los andaluces de la frontera de este reino, los de Badajoz y las gentes de otros muchos pueblos inclinadas al partido de D. Fernando, iban diariamente asolando la región más feraz de Portugal (...) era indispensable [para el rey de Portugal] atender muy particularmente a aquellas apartadas provincias portuguesas, para que mientras él, en el centro del territorio atravesado por el Duero, trabajaba por ocupar Zamora y Toro, no quedasen destruidas las demás provincias, con vergüenza y oprobio considerable"67.

De hecho, según el cronista portugués García de Resende, el príncipe Juan de Portugal tuvo que regresar apresuradamente a su reino tras la batalla de Toro, en un intento de frenar la actividad militar que estaba llevando a cabo Alonso de Monroy por el Alentejo, tras conquistar Alegrete ${ }^{68}$.

\subsubsection{Instrumentalización política de la población agredida}

El hecho de que en numerosas ocasiones la figura del no combatiente (y sus modos de producción) se convirtiera en el objetivo de los ataques se debía a un intento de instrumentalizar políticamente a este sector social a través del terror ${ }^{69}$. El impacto psicológico y la desesperación de toda aquella sociedad que se ha visto abocada a la ruina, junto a la desmoralización del conjunto social que padecía los efectos de las incursiones, constituían un importante factor a tener en cuenta. Y es que, con el paso del tiempo, toda esta angustia podía derivar en un foco de presión hacia sus respectivos dirigentes, para que éstos cesaran su política militar o alcanzaran un acuerdo político con el enemigo que las causaba ${ }^{70}$.

\footnotetext{
66 Fernando del Pulgar, Crónica de los Reyes Católicos, ed. Juan de Mata Carriazo, Espasa-Calpe, Madrid, 1943, p. 148.

67 Alonso de Palencia, Crónica de Enrique IV..., volumen II, p. 247.

68 García de Resende, Vida e feitos..., cap. XV.

69 Christopher Allmand, La Guerra de los Cien Años. Inglaterra y Francia en Guerra, Crítica, Barcelona, 1989 , p. 88.

70 Francisco García Fitz, Castilla León frente..., pp. 106-109.
} 
Como puede apreciarse en el caso concreto de la guerra luso-castellana de 1475, tras dos duros años de muertes, robos, incendios y destrucción del territorio, los súbditos de Alfonso V reclamaron a su príncipe que se pusiera fin a las hostilidades, puesto que ya no podían soportar más los efectos de las acometidas castellanas:

"Su principe D. Juan dando oídos a las quejas de sus vasallos, víctimas del hambre y de los daños de las incursiones de los castellanos, prefirió a la guerra las treguas, y por consejo del Obispo de Évora envió emisarios a ratificarlas y hacerlas bastante duraderas para que permitieran procurarse mantenimientos" $"$.

Dicha tregua terminaría por concretarse a mediados de 1477 (afectando a un espacio geográfico que iba desde Alburquerque hasta Andalucía), siendo Suárez de Figueroa el encargado de asentar las paces con Portugal ${ }^{72}$.

\subsubsection{Finalidad económica}

Lo que para un territorio significaba una pérdida, para un ejército agresor significaba una ganancia. En el contexto de la guerra fronteriza que mantuvieron castellanos y portugueses en 1475 , hemos de decir que la guerra se erigió como una oportunidad económica que permitía a los caudillos de las expediciones autofinanciar sus propias campañas $^{73}$. Como puede apreciarse en el caso concreto de Alonso de Monroy:

"El clavero, Alfonso de Monroy, que también se llamaba Maestre de Calatrava [en realidad era de Alcántara], empezó a molestar a los enemigos talando los campos y manteniendo una escogida caballería ligera con el botín que les arrebataba" 74 .

Ahora bien, convendría señalar que la obtención de un beneficio económico en tiempos de guerra no sólo provino de una forma directa, con el saqueo del territorio tras una acción militar. A este respecto, hemos de decir que, en numerosas ocasiones, el lucro procedió de la exigencia de un pago por rescate. Precisamente, la crónica de Orozco y Juan de la Parra alude a que Alonso de Cárdenas, durante sus incursiones por el interior de Portugal, ocasionaba "grandes daños i tomas de ganado i prisiones i rescates de ombres 75 ". En este sentido,

\footnotetext{
71 Alonso de Palencia, Crónica de Enrique IV..., volumen III, pp. 58-59.

72 Antonio de la Torre y Luis SuÁrez Fernández (eds.), Documentos referentes a ..., volumen I, doc. 63. Ver también: Saul António Gómes, D. Afonso V..., p. 296.

73 Juan L. DE la Montaña Conchiña, “Guerra y sociedad..., p. 509.

74 Alonso de Palencia, Crónica de Enrique IV..., volumen II, p. 280.

75 Pedro de Orozco y Juan de la Parra, Primera historia de..., p. 400.
} 
el coste del rescate de la población civil (que hemos podido constatar) pudo llegar a alcanzar un montante económico que oscilaba en torno a los 1.000 maravedíes por persona ${ }^{76}$. Una práctica de extorsión que incluso llegó afectar a las cabañas ganaderas. Resulta bastante ilustrativo a este respecto lo sucedido a un vecino de la pequeña localidad extremeña de Brozas, que se quejaba amargamente a las autoridades de que los alcaides de Alburquerque y de la Codosera le habían robado unas 800 ovejas y 20 cabras, cifrándose su precio en unos 80.000 maravedís. Lo interesante del caso es que este robo se produjo cuando el propio damnificado atravesaba la frontera de Portugal con su ganado, de donde previamente lo "avía rescatado" de un robo anterior ${ }^{77}$.

\subsubsection{Finalidad logística}

Debido de las carencias logísticas que padecieron los ejércitos del Medievo, las diferentes partidas que estuvieron operando en este sector de la frontera se vieron abocadas a vivir sobre el terreno, a costa de los recursos y los víveres que extraían de las poblaciones por donde transitaban, por lo que bien podemos decir que el saqueo de un territorio también cumplió un importante papel logístico. En este sentido, cuando Alonso de Palencia narra la conquista de Alegrete por Alonso de Monroy, el cronista alude muy significativamente a que este capitán "se reservó abundante provisión de mantenimientos, pues encontró las trojes atestadas de trigo y cebada, y grandes cantidades de vino, aceite y demás vituallas con que alimentar a sus soldados durante dos años"78.

De igual manera, resulta también bastante ilustrativo lo sucedido con las expediciones que Suárez de Figueroa y Medina Sidonia enviaban sobre los dominios santiaguistas contra Alonso de Cárdenas. Como refleja Andrés Bernáldez en su crónica, la subsistencia de estos ejércitos se fundamentó en el robo y la extorsión:

"les tomaron e robaron aquellas gentes de guerra muchos ganados, bueyes e vacas e ovejas, e ovo hatos de ochocientas ovejas e otros de menos en que ni una dexaron, que todas las comieron sin las pagar (...) e les avían comido sus vacas e ovejas e ganados, según dicho es"79.

\subsubsection{La incursión como maniobra complementaria de otra acción mayor}

Por último, no quisiera dejar de mencionar una finalidad muy importante que podían llegar a cumplir estas maniobras de devastación, como era la de distraer a un oponente.

\footnotetext{
76 Antonio de la Torre y Luis SuÁrez Fernández (eds.), Documentos referentes a ..., volumen I, doc. 77.

77 Bonifacio Palacios Martín (dir.), Colección diplomática medieval de la Orden de Alcántara. volumen II, doc. 1240 .

78 Alonso de Palencia, Crónica de Enrique IV..., volumen II, p. 281.

79 Andrés BeRnÁldez, Memorias del reinado..., pp. 88-89.
} 
En este sentido, Alonso de Monroy, para apoderarse de la villa de Alegrete, más que plantear una maniobra de asedio utilizó una acción de devastación a modo de distracción. De manera que, al talar los campos cercanos a Alegrete, este caudillo castellano hizo salir de la villa a la guarnición que la custodiaba, quedando entonces la población desguarnecida y en una situación de extremada vulnerabilidad:

"Preparado así todo con gran sigilo, envió talar los campos de los pueblos del término de Alegrete a unos cuantos jinetes de los 300 de los que se había reservado. En cuanto los de la villa percibieron la voz de alarma, corrieron desaforados en auxilio de los amigos; nuestros jinetes cedieron el paso, y fingiendo gran espanto, fueron abandonando la presa a los enemigos que les perseguían. Vacilaban éstos en seguir el alcance; pero se consideraban a cubierto de todo desastre por lo próximo que se creían de la villa y por no ver peligro alguno que les amenazara. Entonces, los de las celadas, en cuanto conocieron por las señas de los corredores que, a excepción de las mujeres, niños, y ancianos, todos los de la villa estaban desparramados por el campo, destacaron a los más resueltos para apoderarse rápidamente de la puerta de la población. Siguiéronles al punto los demás, que, a su vez, hicieron señales al caudillo D. Alfonso de estar ocupada la entrada" $"$.

\section{Conclusión}

En función de las ideas aquí expuestas, estamos en condiciones de afirmar que los territorios de frontera tuvieron una gran actividad militar durante el inicio de la Guerra de Sucesión, y no sólo al final de esta contienda (como en numerosas ocasiones se ha venido argumentando). En este sentido, creemos que resulta erróneo seguir sosteniendo la idea de que, entre los años de 1478 y 1479, la actividad militar se desplazó desde la Meseta a la frontera portuguesa. En todo caso, de producirse un desplazamiento, éste se correspondería con el de los protagonistas del conflicto, pero no con la actividad militar. De hecho lo que realmente parece advertirse es que, desde el inicio del conflicto sucesorio, hubo dos frentes claramente diferenciados (Meseta/frontera) que tuvieron un gran protagonismo, desapareciendo desde 1477 el del Duero y prolongando su vigencia el fronterizo hasta 1479.

Es precisamente por todo este conjunto de razones por las que abogamos y defendemos un estudio de las campañas militares desde una perspectiva global, al margen de la actividad militar que Fernando el Católico y Alfonso V pudieron llevar a cabo, por cuanto la imagen que podemos tener de esta guerra puede quedar un tanto deformada, al ser silenciada la acción militar trasfronteriza.

80 Alonso de Palencia, Crónica de Enrique IV ..., volumen II, p. 281. 


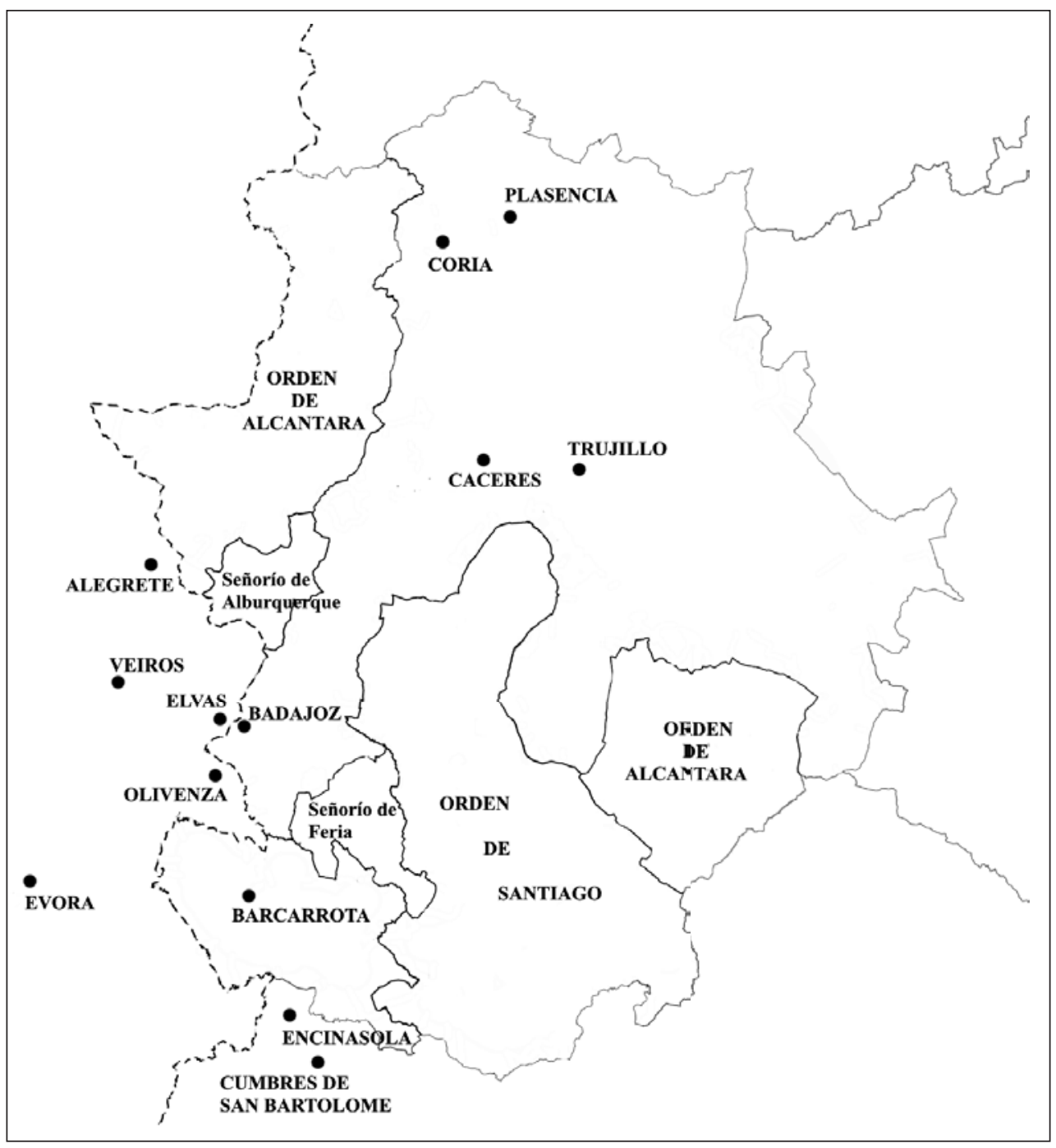

Elaboración propia.

Fecha de recepción: 8 de marzo de 2017

Fecha de aceptación: 21 de abril de 2017 
